\title{
Activation of the GABAergic Parafacial Zone Maintains Sleep and Counteracts the Wake-Promoting Action of the Psychostimulants Armodafinil and Caffeine
}

\author{
Christelle Anaclet ${ }^{*, 1,2}$, Kobi Griffith' and Patrick M Fuller' \\ 'Division of Sleep Medicine, Department of Neurology, Beth Israel Deaconess Medical Center, Harvard Medical School, Boston, MA, USA; \\ ${ }^{2}$ Department of Neurobiology, University of Massachusetts Medical School, Worcester, MA, USA
}

\begin{abstract}
We previously reported that acute and selective activation of GABA-releasing parafacial zone (PZ ${ }^{\text {Vgat }}$ ) neurons in behaving mice produces slow-wave-sleep (SWS), even in the absence of sleep deficit, suggesting that these neurons may represent, at least in part, a key cellular substrate underlying sleep drive. It remains, however, to be determined if $\mathrm{PZ} \mathrm{V}^{\mathrm{gat}}$ neurons actively maintain, as oppose to simply gate, SWS. To begin to experimentally address this knowledge gap, we asked whether activation of PZ ${ }^{\mathrm{Vgat}}$ neurons could attenuate or block the wakepromoting effects of two widely used wake-promoting psychostimulants, armodafinil or caffeine. We found that activation of $\mathrm{PZ} Z^{\vee g a t}$ neurons completely blocked the behavioral and electrocortical wake-promoting action of armodafinil. In some contrast, activation of PZ ${ }^{\vee g a t}$ neurons inhibited the behavioral, but not electrocortical, arousal response to caffeine. These results suggest that: (I) PZ Vgat neurons actively maintain, as oppose to simply gate, SWS and cortical slow-wave-activity; (2) armodafinil cannot exert its wake-promoting effects when PZ ${ }^{\text {Vgat }}$ neurons are activated, intimating a possible shared circuit/molecular basis for mechanism of action; (3) caffeine can continue to exert potent cortical desynchronizing, but not behavioral, effects when $\mathrm{PZ} \mathrm{Vgat}^{\mathrm{V}}$ neurons are activated, inferring a shared and divergent circuit/ molecular basis for mechanism of action; and 4) PZ ${ }^{V g a t}$ neurons represent a key cell population for SWS induction and maintenance. Neuropsychopharmacology (2018) 43, 4I5-425; doi:I0.1038/npp.2017.152; published online 16 August 2017
\end{abstract}

\section{INTRODUCTION}

The neuronal mechanisms controlling slow-wave-sleep (SWS, also called NREM sleep) remain incompletely understood. In a recent series of studies, we uncovered a delimited node of GABAergic SWS-promoting neurons in the rostral medullary parafacial zone $\left(\mathrm{PZ}^{\text {Vgat }}\right)$, and showed that acute and selective activation of these neurons potently drove SWS, even during the early active period when sleep drive is minimal (Anaclet et al, 2014; Anaclet et al, 2012). Interestingly, this induced SWS shared several key characteristics with physiologic 'rebound' sleep, for example, increased sleep time, consolidation and elevated cortical slow-wave activity [SWA; (Anaclet et al, 2014)], suggesting that $\mathrm{PZ}{ }^{\text {Vgat }}$ neurons may also play a key role in sleep homeostasis. The synaptic and circuit basis by which $\mathrm{PZ}{ }^{\mathrm{Vgat}}$ neurons produce sleep remains unresolved, although a functional polysynaptic pathway from the $\mathrm{PZ}$ to the cortex, via the wake-promoting parabrachial nucleus and basal forebrain (Anaclet et al, 2015; Fuller et al, 2011), has been implicated (Anaclet et al, 2014).

\footnotetext{
*Correspondence: Dr C Anaclet, Department of Neurobiology, University of Massachusetts Medical School, Lazare Research Building, Room 719, 364 Plantation Street, Worcester, MA 01605-2324, USA. Tel: +508 856 4l I7, Fax: +508 8562495 ,

E-mail: Christelle.Anaclet@umassmed.edu

Received 2 May 2017; revised 5 July 2017; accepted 13 July 2017; accepted article preview online 19 July 2017
}

It nevertheless remains to be clarified whether $\mathrm{PZ}^{\mathrm{Vgat}}$ neurons are actively involved in maintaining SWS, as opposed to simply triggering or passively gating SWS. Our working hypothesis is that activation of $\mathrm{PZ}{ }^{\text {gat }}$ neurons produces and maintains cortical synchronization and SWS through both inhibition of wake-promoting circuitries (passive gating) as well as via an as yet unknown active mechanism.

To begin to experimentally address this hypothesis, we asked whether activation of $\mathrm{PZ}{ }^{\text {Vgat }}$ neurons could attenuate or block the wake-promoting and cortical desynchronizing effects of two widely used wake-promoting psychostimulants, armodafinil and caffeine. We predicted that the SWS induced by activation of $\mathrm{PZ} \mathrm{V}^{\mathrm{Vgat}}$ neurons would be strongly attenuated, possibly even blocked, by administration of armodafinil or caffeine if $\mathrm{PZ}^{\mathrm{Vgat}}$ neurons function simply to 'gate' SWS. If, on the other hand, $\mathrm{PZ}^{\mathrm{Vgat}}$ neurons actively maintain SWS, we would predict that their sustained activation would counteract the wake-promoting effects of armodafinil and caffeine. We chose to use both armodafinil and caffeine on the basis that, while these compounds are both wake-promoting, they are also largely divergent in their wake-promoting mechanism of action. For example, modafinil is a weak, but apparently very selective, dopamine transporter (DAT) inhibitor, and appear to activate multiple wake-promoting circuits (Fiocchi et al, 2009; Lin et al, 1996; Scammell et al, 2000). ( \pm )modafinil (modafinil) and its 
R-enantiomer, armodafinil, may also inhibit the sleep-promoting ventrolateral preoptic nucleus (VLPO) (Cornil et al, 2002; Gallopin et al, 2004; Scammell et al, 2000), although lesions of the VLPO do not block the wakepromoting effects of armodafinil (Vetrivelan et al, 2014). By contrast, caffeine is an adenosine $\mathrm{A} 1$ and $\mathrm{A} 2 \mathrm{~A}$ receptor antagonist and it has been shown that $\mathrm{A} 2 \mathrm{~A}$ receptors in the shell region of the nucleus accumbens are a critical substrate for caffeine's wake-promoting action (Lazarus et al, 2011). Both modafinil and caffeine do, however, promote dopamine signaling (Galvalisi et al, 2017; Nall et al, 2016; Volkow et al, 2015; Wisor, 2013).

\section{MATERIALS AND METHODS}

\section{Animals}

Adult male Vgat-IRES-cre mice (Vong et al, 2011) and noncre-expressing littermate mice (8-12 weeks, 20-25 g; $n=46$ ) were used in this study. Mice were bred at our animal facility and underwent genotyping both before and after experiments. All procedures were approved by the Institutional Animal Care and Use Committee of Beth Israel Deaconess Medical Center.

\section{Surgery}

Naive mice were anesthetized with ketamine/xylazine (100 and $10 \mathrm{mg} / \mathrm{kg}$, respectively, intraperitoneal (IP)) and then placed in a stereotaxic apparatus. To selectively express the hM3Dq receptors in GABAergic (VGAT+) neurons of the PZ, we placed bilateral injections of an adeno-associated viral (AAV; serotype 10) vector expressing the hM3Dq receptor in a cre-dependent configuration (hSyn-DIO-hM3Dq-mCherryAAV; (Anaclet et al, 2014)) into the PZ (coordinates: Antero-Posterior $=-5.3 \mathrm{~mm}$, Lateral $= \pm 0.7 \mathrm{~mm}$, Dorsoventral $=-3.4 \mathrm{~mm}$, as per the mouse atlas of Paxinos and Watson (Paxinos and Franklin, 2001)) of Vgat-IRES-cre mice $\left(\mathrm{PZ} \mathrm{Vgat}^{\mathrm{VM} 3 \mathrm{Dq}}\right)$. As vector injection controls, we injected the same viral vector into the $\mathrm{PZ}$ of non-cre expressing littermate mice $\left(\mathrm{PZ}^{\mathrm{Vgat}-\mathrm{wt}}\right)$. Injections of the viral vector $(60 \mathrm{nl})$ into the $\mathrm{PZ}$ of these mice were performed using a compressed air delivery system as previously described (Anaclet et al, 2010). After injections, mice were implanted with four EEG screw electrodes (Pinnacle Technology Inc.) and two flexible electromyogram (EMG) wire electrodes (Plastics One), previously soldered to a 6-pin connector (Pinnacle Technology Inc.) and the assembly was secured with dental cement. The scalp wound was closed with surgical sutures and the mouse was kept in a warm environment until resuming normal activity as previously described (Anaclet et al, 2015).

\section{Sleep-Wake Monitoring}

Three weeks after surgery, the mice were housed individually in transparent barrels in an insulated sound-proofed recording chamber maintained at an ambient temperature of $22 \pm 1{ }^{\circ} \mathrm{C}$ and on a $12 \mathrm{~h}$ light/dark cycle (lights-on at 07:00 A.M., Zeitgeber time: ZT0) with food and water available ad libitum. Mice were habituated to the recording cable for 5-7 days before starting polygraphic recording. Cortical EEG (ipsilateral fronto-parietal leads) and EMG signals were amplified and digitalized with a resolution of $500 \mathrm{~Hz}$ using Vital recorder (Kissei, Japan). Mice were recorded for $24 \mathrm{~h}$ baseline period followed by intraperitoneal injections of saline (control injection), Clozapine-N-oxide (CNO, Sigma-Aldrich; $0.3 \mathrm{mg} / \mathrm{kg}$ in saline), armodafinil (Cephalon; 90 and $180 \mathrm{mg} / \mathrm{kg}$ in saline), caffeine (Sigma; 5 and $20 \mathrm{mg} / \mathrm{kg}$ in saline), CNO plus armodafinil and CNO plus caffeine. Injections were performed at 10:00 A.M. (ZT3, light period, time of high sleeping drive), in a randomized cross-over design, with each injection separated by a 3-5 day washout period. In each experiment, recordings were simultaneously made from an equal number (batches of 2-4) of $\mathrm{PZ}$ Vgat-hM3Dq and $\mathrm{PZ}$ Vgat-wt mice.

\section{Sleep Scoring and Analysis}

Using SleepSign for Animal (Kissei, Japan) and with assistance of spectral analysis using fast Fourier transform, polygraphic records were visually scored by $10 \mathrm{~s}$ epochs for wakefulness (W), slow-wave-sleep (SWS), and rapid eye movement (REM) sleep. The percentage of time spent in wake, SWS and REM sleep were summarized for each group and each condition. The latency to SWS and REM sleep are defined as the time between the end of the injection and the onset of the first SWS episode lasting $>20 \mathrm{~s}$ and the first REM sleep episode lasting $>10 \mathrm{~s}$.

Recordings were scored again in $5 \mathrm{~s}$ epochs to allow for performance of an EEG power spectrum analysis. On the basis of visual and spectral analysis, epochs containing artifacts occurring during active wake (with large movements) or containing two vigilance states were visually identified and omitted from the spectral analysis. Recordings containing wake artifacts during $>20 \%$ of the time were removed from the spectral analysis. EEG power spectra were computed for consecutive $5 \mathrm{~s}$ epochs within the frequency range of $0.5-120 \mathrm{~Hz}$ using a fast Fourier transform routine (FFT). The data were collapsed into $0.5 \mathrm{~Hz}$ bins. To determine the effect of injection on sleep-wake power spectra of $\mathrm{PZ} \mathrm{Vgat}^{\text {VaM3Dq }}$ and $\mathrm{PZ} \mathrm{V}^{\text {Vat-wt }}$ mice, EEG power spectra were analyzed during the $1-3 \mathrm{~h}$ period of time post injection, starting $10 \mathrm{~min}$ after injection as CNO injection significantly affects SWS amount during $3 \mathrm{~h}$ post injection and SWS latency is no more than $10 \mathrm{~min}$ in $\mathrm{PZ}_{\mathrm{Vgat}-\mathrm{hM}} \mathrm{Dq}$ mice (Anaclet et al, 2014). The data were standardized by expressing each frequency bin as a percentage relative to the same bin in baseline condition from the same mouse and from the same time of the day (same Zeitgeber time). To analyze the EEG frequency bands, power bins were summed in $\delta: 0.5-5 \mathrm{~Hz}, \theta: 5-9 \mathrm{~Hz}, \alpha: 9-15 \mathrm{~Hz}, \beta: 15-30 \mathrm{~Hz}$, low $\gamma: 30-$ $60 \mathrm{~Hz}$ and high $\gamma: 60-120 \mathrm{~Hz}$, and expressed in percentage of baseline power band, from the same circadian time.

\section{Statistical Analysis}

Statistical analysis was performed using Prism v6 (GraphPad Software, San Diego, CA, USA). Following confirmation that the data met the assumptions of the ANOVA model, twoway ANOVA followed by a post hoc Bonferroni test were used to compare the effects of the drug injection and time period on sleep-wake parameters or the effect of drug injection and power band on cortical EEG power density. 

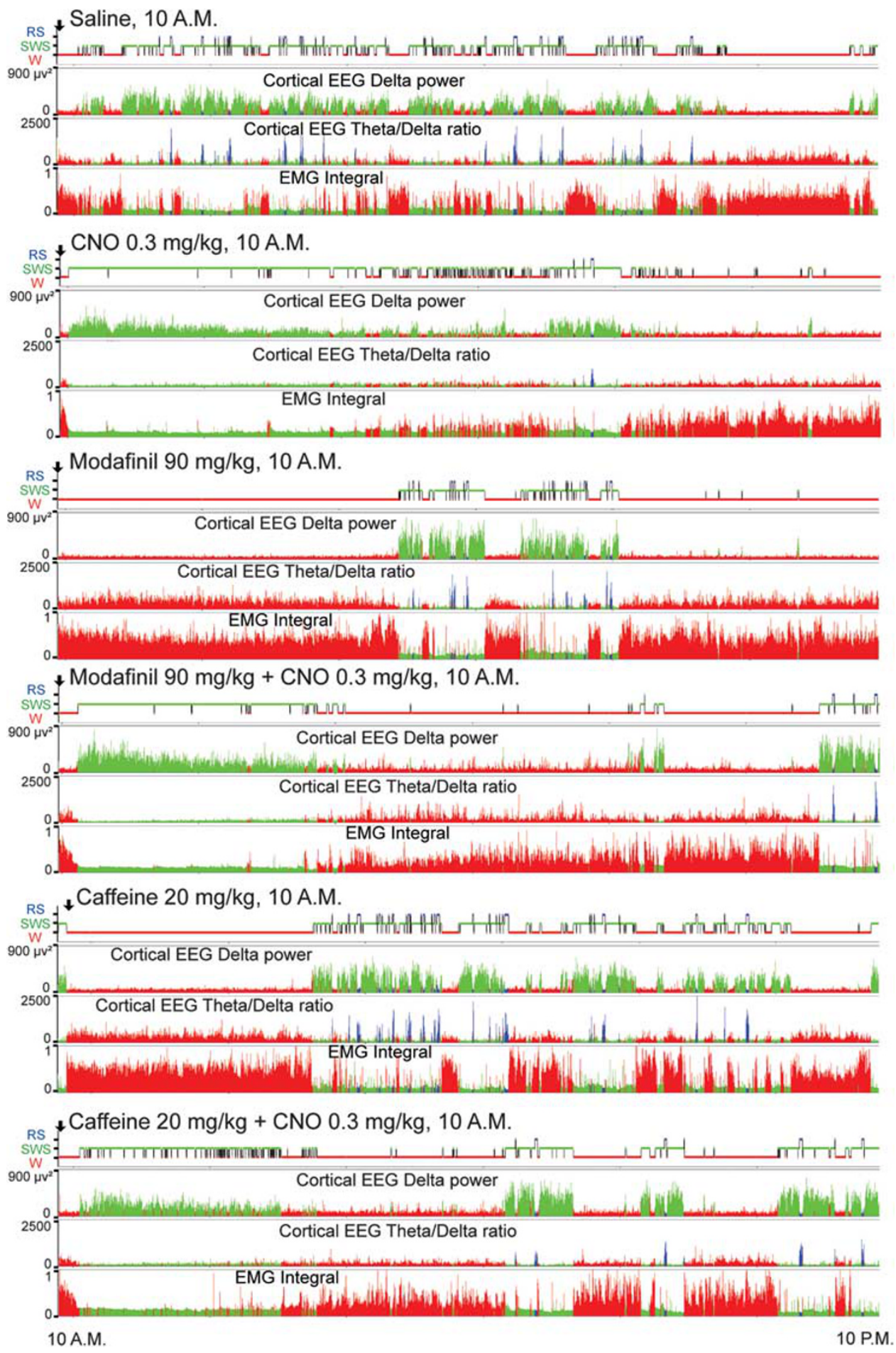

Figure I Example $12 \mathrm{~h}$ recordings showing hypnograms and corresponding cortical EEG delta power, theta/delta ratio and EMG activity following injection of vehicle, CNO $0.3 \mathrm{mg} / \mathrm{kg}$, armodafinil $90 \mathrm{mg} / \mathrm{kg}$, CNO $0.3 \mathrm{mg} / \mathrm{kg}+$ armodafinil $90 \mathrm{mg} / \mathrm{kg}$, caffeine $20 \mathrm{mg} / \mathrm{kg}$ and CNO $0.3 \mathrm{mg} / \mathrm{kg}+\mathrm{caffeine} 20 \mathrm{mg} / \mathrm{kg}$ at I0:00 A.M. in a PZ Vgat-hMMBq mouse. Red, wakefulness; green, SWS; blue, REM sleep.

One-way ANOVA followed by a post hoc Bonferroni test were used to compare the effects of the drug injection on sleep latency. Sample size and power calculations were performed post hoc at http://www.biomath.info, using means and standard deviations derived from our analysis. The present study was sufficiently powered to detect effect sizes.

\section{RESULTS}

\section{Activation of $\mathrm{PZ}{ }^{\text {Vgat }}$ Neurons Blocks the Wake-Promoting Action of Armodafinil}

To test whether activation of $\mathrm{PZ}{ }^{\text {Vgat }}$ neurons can block the arousal-promoting effects of armodafinil, nine mice expressing the excitatory $\mathrm{hM} 3 \mathrm{Dq}$ receptor in PZ GABAergic 

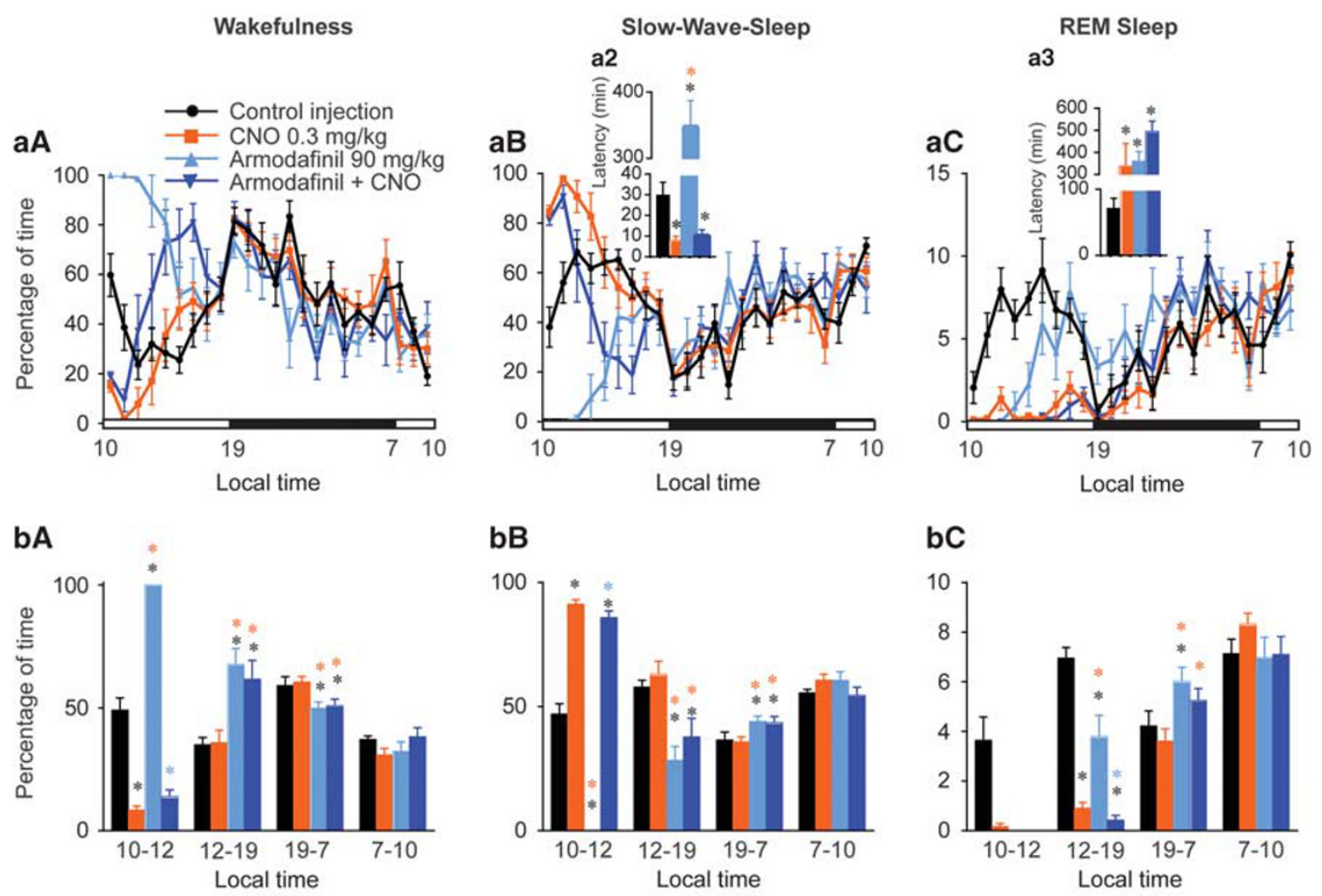

bC
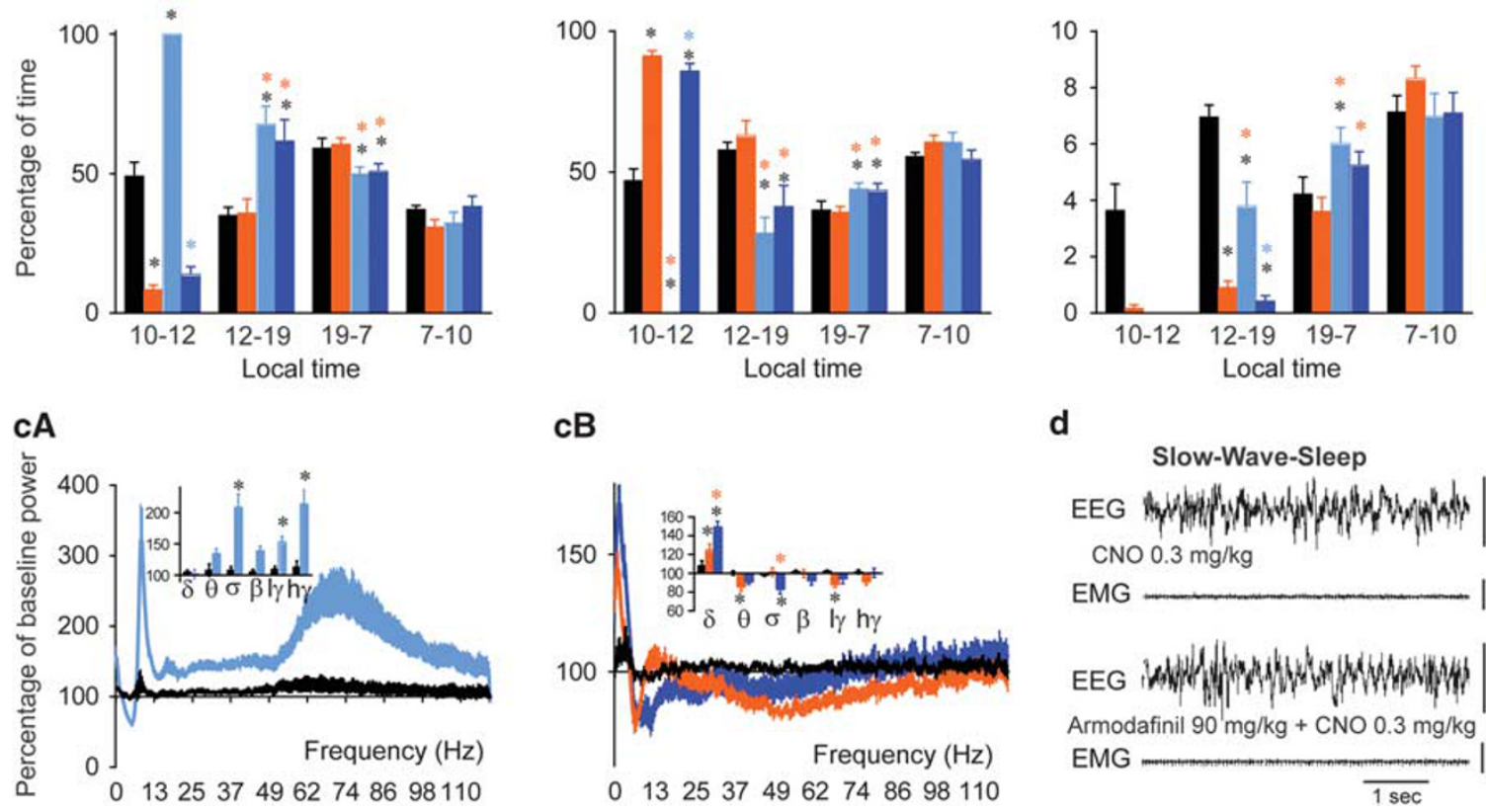

d

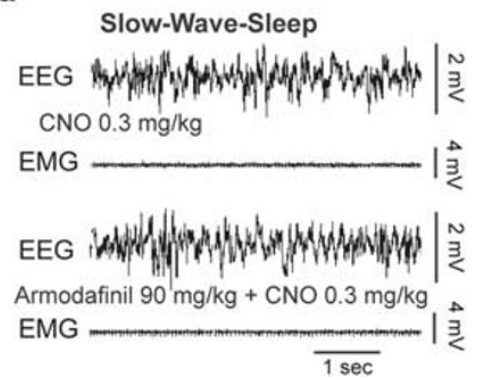

Figure 2 Sleep-wake and EEG responses to injections of vehicle, CNO $(0.3 \mathrm{mg} / \mathrm{kg})$, armodafinil $(90 \mathrm{mg} / \mathrm{kg})$ and CNO+armodafinil $(0.3 \mathrm{mg} / \mathrm{kg}$ and 90 $\mathrm{mg} / \mathrm{kg}$, respectively) in $\mathrm{PZ} \mathrm{Vgat}^{\mathrm{VM} 3 \mathrm{Dq} q}$ mice. (a) Hourly amount of the vigilance stages and (a2-3) sleep latencies, $n=9$ mice. (b) Amount of the vigilance stages during the $2 \mathrm{~h}$ post injection (10:00-12:00), the rest of the light period (12:00-19:00), the following dark period (19:00-7:00) and the first $3 \mathrm{~h}$ of the light period the next day (07:00-10:00), n=9 mice. (c) Power spectrum changes (\% \pm SEM) over baseline during the $3 \mathrm{~h}$ post-injection period for vehicle injection as compared with the I h post-injection period for CNO, armodafinil and CNO+armodafinil administration, and the quantitative changes (\% \pm SEM) in power for the delta $(\delta: 0.5-5 \mathrm{~Hz})$, theta $(\theta: 5-9 \mathrm{~Hz})$, sigma $(\sigma: 9-15 \mathrm{~Hz})$, beta $(\beta$ : I $5-30 \mathrm{~Hz})$, low gamma $(\mathrm{l}$ : $30-60 \mathrm{~Hz})$ and high gamma (hy: 60- $120 \mathrm{~Hz})$ frequency bands, $n=8$ mice. Black star, $p<0.05$ as compared with control injection; orange star, $p<0.05$ as compared with CNO injection; light blue star, $p<0.05$ as compared with armodafinil injection, two-way ANOVA corrected with a Bonferroni's multiple comparisons test. (d) Raw EEG/EMG examples showing SWS following injection of $\mathrm{CNO}$ or $\mathrm{CNO}+$ armodafinil from the same mouse.

neurons (PZ ${ }^{\text {Vgat-hM3Dq }}$ mice) were injected in a randomized cross-over design with saline, CNO (hM3Dq ligand, $0.3 \mathrm{mg} /$ $\mathrm{kg})$, armodafinil $(90 \mathrm{mg} / \mathrm{kg})$ or $\mathrm{CNO}+$ armodafinil (0.3 and $90 \mathrm{mg} / \mathrm{kg}$, respectively; Figures 1 and 2). Treatment significantly affected SWS latency (one-way ANOVA, F(1.058,8.464) $=121.9, p<0.0001)$. More specifically, and as previously shown, CNO injection significantly decreased and armodafinil significantly increased SWS latency (Figure 2a2). When CNO and armodafinil were co-injected, SWS latency was similar to CNO injection, indicating that the SWS-inducing action of $\mathrm{PZ}{ }^{\mathrm{Vgat}}$ neurons is not affected by armodafinil at the dose of $90 \mathrm{mg} / \mathrm{kg}$. REM sleep latency was significantly increased after $\mathrm{CNO}$, armodafinil and $\mathrm{CNO}+$ armodafinil injections as compared with control injection (Figure 2a3).

Treatment significantly affected SWS amount during the two hour post-injection (two-way ANOVA, $\mathrm{F}(3,96)=12.08$, $p<0.0001$; Figure $2 \mathrm{bB}$ ). CNO injection significantly increased SWS amount and armodafinil significantly increased wake amount as compared with control injection. Coinjection of $\mathrm{CNO}+$ armodafinil resulted in similar amounts of SWS as compared with $\mathrm{CNO}$ alone, indicating that the SWS-promoting action of $\mathrm{PZ}{ }^{\text {Vgat }}$ neurons is not affected by armodafinil at the dose of $90 \mathrm{mg} / \mathrm{kg}$.

In some contrast to previous reports, a sleep rebound was observed during the dark period following armodafinil 
Wakefulness

aA
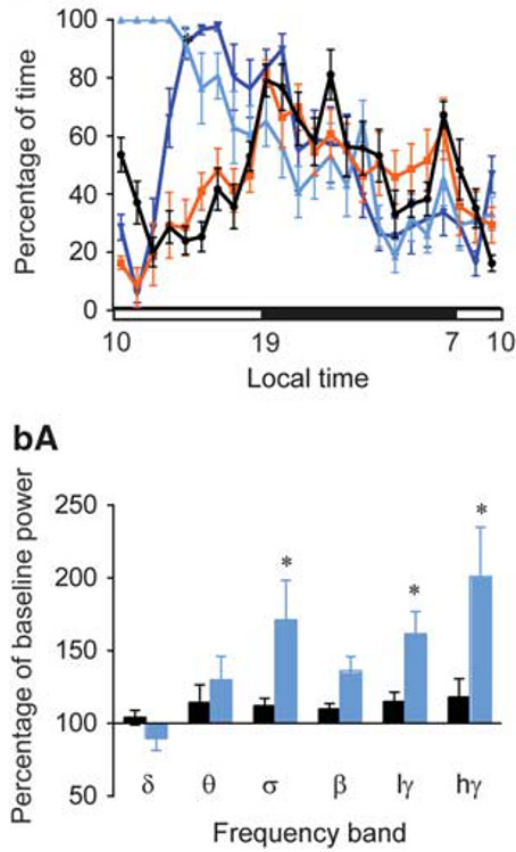

Slow-Wave-Sleep

\section{aB}

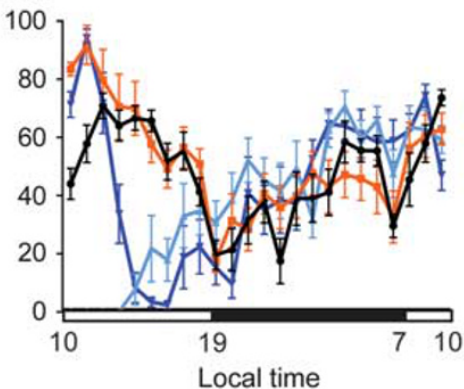

bB

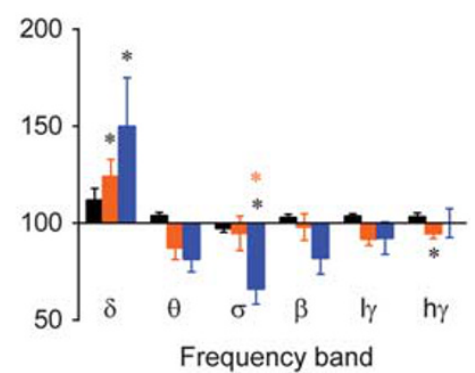

REM Sleep

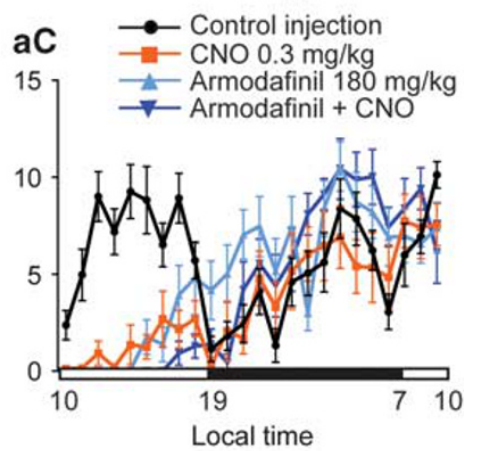

Figure 3 Sleep-wake and EEG responses to injections of vehicle, CNO (0.3 mg/kg), armodafinil (I80 mg/kg) and CNO+armodafinil $(0.3 \mathrm{mg} / \mathrm{kg}$ and $180 \mathrm{mg} / \mathrm{kg}$, respectively), in PZ ${ }^{V g a t-h M 3 D q}$ mice. (a) Hourly amount of the vigilance stages, $n=9$ mice. (b) Power spectrum changes (\% \pm SEM) over baseline during the $3 \mathrm{~h}$ post-injection period for vehicle injection as compared with the I $\mathrm{h}$ post-injection period for $\mathrm{CNO}$, armodafinil and $\mathrm{CNO}+$ armodafinil administration and the quantitative changes $(\% \pm \mathrm{SEM})$ in power for the delta $(\delta: 0.5-5 \mathrm{~Hz})$, theta $(\theta: 5-9 \mathrm{~Hz})$, sigma $(\sigma: 9-15 \mathrm{~Hz})$, beta $(\beta$ : I5-30 Hz), low gamma $(\mid \gamma: 30-60 \mathrm{~Hz})$ and high gamma $(\mathrm{h} \gamma: 60-120 \mathrm{~Hz})$ frequency bands, $n=6$ mice. Black star, $p<0.05$ as compared with control injection; orange star, $p<0.05$ as compared with CNO injection, two-way ANOVA corrected with a Bonferroni's multiple comparisons test.

injection (Figure 2bB). Interestingly, a rebound of SWS but not REM sleep was also observed during the dark period following co-injection of CNO+armodafinil.

Both wakefulness and SWS cortical EEG power spectra were affected by the treatment (Figure 2c). Armodafinil significantly increased sigma, low and high gamma bands during wakefulness, confirming its cortical desynchronizing action. CNO-induced SWS was characterized by a significant increase of the delta band and a significant decrease of theta and low gamma bands. When $\mathrm{CNO}$ and armodafinil were co-injected, SWS cortical EEG was visually indistinguishable from CNO injection (Figure 2d) with enhanced SWA and reduced theta rhythm (Figure $2 \mathrm{cB}$ ). Theta frequency band was similarly decreased after $\mathrm{CNO}$ and $\mathrm{CNO}+$ armodafinil, as compared with control injection. Interestingly, delta power was significantly more enhanced by co-injection of $\mathrm{CNO}$ +armodafinil as compared with $\mathrm{CNO}$ alone, indicating that armodafinil potentiates the cortical synchronizing action and SWA of $\mathrm{PZ}^{\mathrm{Vgat}}$ neurons. Finally, sigma frequency band, spindle frequency range, was significantly decreased by coinjection of $\mathrm{CNO}+$ armodafinil as compared with both $\mathrm{CNO}$ and control injection. Because spindles are more abundant during light sleep and SWA is a marker of SWS intensity/ quality, these results suggest that armodafinil potentiates the sleep-promoting action of $\mathrm{PZ}{ }^{\text {Vgat }}$ neurons.

Armodafinil dose dependently enhanced wake amount in PZ ${ }^{\text {Vgat-wt }}$ mice (Supplementary Table S1). Lack of nonspecific action and/or interaction of $\mathrm{CNO}$ and armodafinil was confirmed by the absence of sleep-wake change between control and CNO injections as well as between armodafinil and $\mathrm{CNO}+$ armodafinil injections in $\mathrm{PZ}^{\text {Vgat-wt }}$ mice (Supplementary Table S1 \& Supplementary Figure S1). These results confirm that $\mathrm{CNO}$ has no non-specific effect on sleepwake phenotype and does not affect the wake-promoting action of armodafinil in $\mathrm{PZ}^{\mathrm{Vgat}-\mathrm{wt}}$, in the absence of hM3Dq receptor.

Because it remains possible that a higher dose of armodafinil would be able to induce wakefulness even when $\mathrm{PZ}^{\mathrm{Vgat}}$ neurons are activated via the excitatory DREADDs, we tested whether or not armodafinil at a dose of $180 \mathrm{mg} / \mathrm{kg}$ would be sufficient to promote wakefulness when $\mathrm{PZ}^{\text {vgat }}$ neurons are activated, in $\mathrm{PZ}{ }^{\mathrm{Vgat}-\mathrm{hM} 3 \mathrm{Dq}}$ mice. Similar results were observed between armodafinil 90 and $180 \mathrm{mg} / \mathrm{kg}$ (Figures 2 and 3). At the high dose, the wake-promoting action of armodafinil lasted longer. As compared to their respective control injections, armodafinil $(180 \mathrm{mg} / \mathrm{kg})$ significantly increased wakefulness during $7 \mathrm{~h}$ following the injection (Figure $3 \mathrm{aA}$ ), whereas wakefulness was significantly increased during $5 \mathrm{~h}$ after $90 \mathrm{mg} / \mathrm{kg}$ dosing (Figure 2aA). But activation of $\mathrm{PZ}^{\text {Vgat }}$ neurons was still able to counteract the wake-promoting action of armodafinil and induced SWS during the $2 \mathrm{~h}$ following the co-injection of armodafinil $(180 \mathrm{mg} / \mathrm{kg})+\mathrm{CNO}$. Moreover, CNO was still able to increase SWS delta power band when co-injected with armodafinil $180 \mathrm{mg} / \mathrm{kg}$ (Figure $3 \mathrm{bB}$ ). These results indicate that activation of $\mathrm{PZ}{ }^{\mathrm{Vat}}$ neurons completely block the wake-promoting action of armodafinil. Interestingly, after the two first hours post armodafinil $(180 \mathrm{mg} / \mathrm{kg})+\mathrm{CNO}$ injection, wakefulness 
Wakefulness
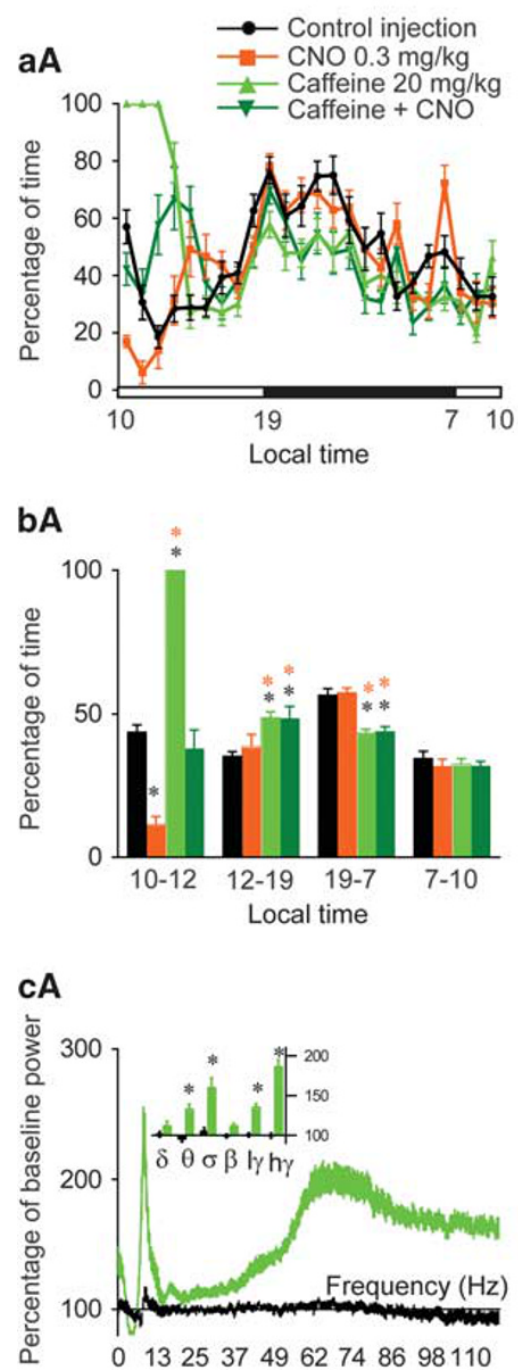

Slow-Wave-Sleep

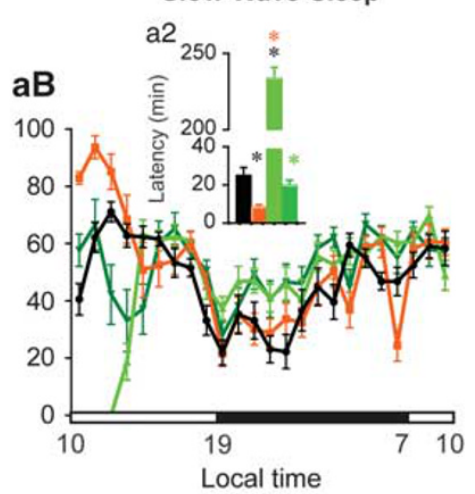

bB

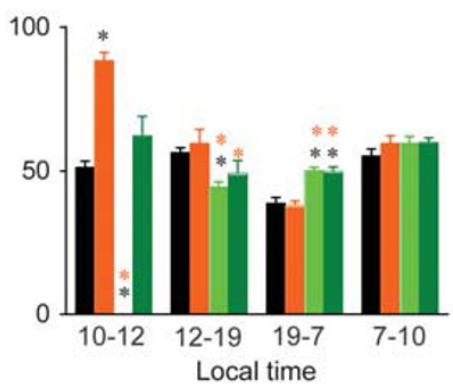

cB

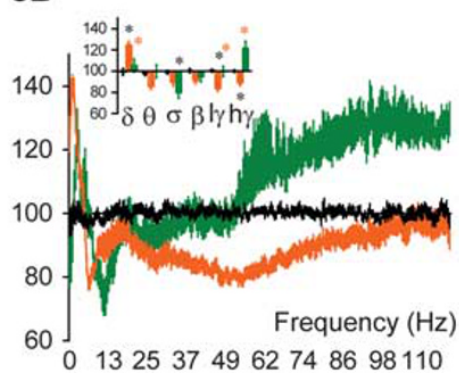

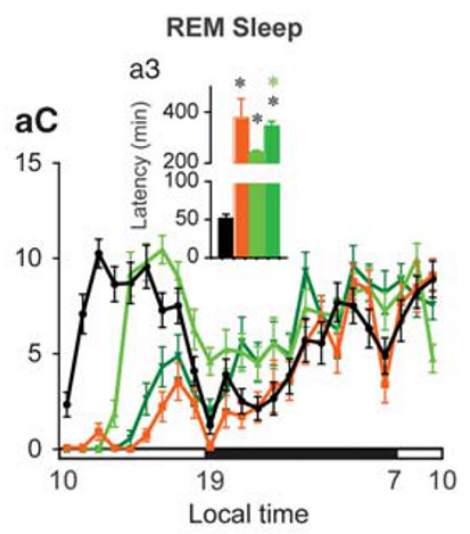

bC

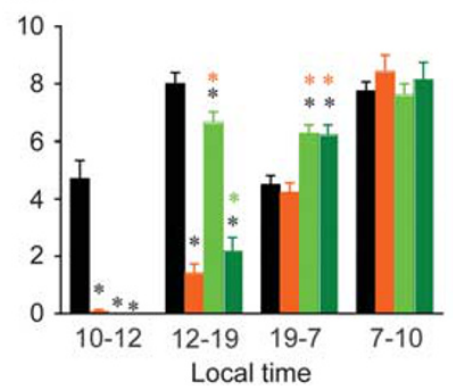

d
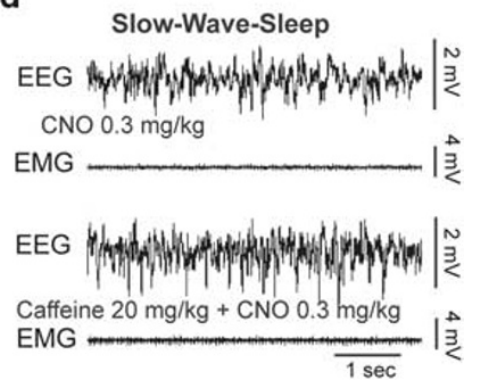

Figure 4 Sleep-wake and EEG responses to injections of vehicle, CNO $(0.3 \mathrm{mg} / \mathrm{kg})$, caffeine $(20 \mathrm{mg} / \mathrm{kg})$ and $\mathrm{CNO}+\mathrm{caffeine}(0.3 \mathrm{mg} / \mathrm{kg}$ and $20 \mathrm{mg} / \mathrm{kg}$, respectively), in $\mathrm{PZ}{ }^{\mathrm{Vgat}-\mathrm{hM} 3 \mathrm{Dq}}$ mice. (a) Hourly amount of the vigilance stages and (a2-3) sleep latencies, $n=15$ mice. (b) Amount of the vigilance stages during the 2-h post injection (10:00-12:00), the rest of the light period (12:00-19:00), the following dark period (19:00-7:00) and the first $3 \mathrm{~h}$ of the light period the next day (7:00-10:00), $n=15$ mice. (c) Power spectrum changes $(\% \pm S E M)$ over baseline during the $3 \mathrm{~h}$ post-injection period for vehicle injection as compared with the I $\mathrm{h}$ post-injection period for $\mathrm{CNO}$, caffeine and $\mathrm{CNO}+$ caffeine administration and the quantitative changes (\% \pm SEM) in power for the delta $(\delta: 0.5-5 \mathrm{~Hz})$, theta $(\theta: 5-9 \mathrm{~Hz})$, sigma $(\sigma: 9-15 \mathrm{~Hz})$, beta $(\beta$ : $15-30 \mathrm{~Hz})$, low gamma $(1 \gamma: 30-60 \mathrm{~Hz})$ and high gamma (hy: 60-I20 Hz) frequency bands, $n=10$ mice. Black star, $p<0.05$ as compared with control injection; orange star, $p<0.05$ as compared with CNO injection; light green star, $p<0.05$ as compared with caffeine injection, two-way ANOVA corrected with a Bonferroni's multiple comparisons test. (d) Raw EEG/EMG examples showing SWS following injection of $\mathrm{CNO}$ or $\mathrm{CNO}+$ caffeine.

was significantly increased as compared with both control and $\mathrm{CNO}$ injections, resulting in a similar amount of wakefulness as compared with armodafinil $(180 \mathrm{mg} / \mathrm{kg}$; Supplementary Table S2). This could be explained by the pharmacokinetics of $\mathrm{CNO}$ and armodafinil. CNO plasma concentration reaches a maximum 15 mins after intraperitoneal injection and is no longer detectable after two hours post-injection (Wess et al, 2013). This observation suggests that $\mathrm{PZ}{ }^{\text {Vat }}$ inhibition of wake-promoting action of armodafinil is reversible.

These results show that acute and specific activation of $\mathrm{PZ}^{\text {Vgat }}$ neurons completely inhibits the wake-promoting action of armodafinil and this effect is reversible, not dose-dependent (up to $180 \mathrm{mg} / \mathrm{kg}$ ) or due to a non-specific inhibition of armodafinil action in the brain.

\section{Activation of $\mathrm{PZ}^{\mathrm{Vgat}}$ Neurons Counteracts the Wake-Promoting Action of Caffeine}

To test if caffeine can induce wakefulness and block the sleep-promoting action of $\mathrm{PZ}{ }^{\text {Vgat }}$ neuronal activation, 15 $\mathrm{PZ}$ gat-hM3Dq mice were injected in a randomized cross-over design with saline, $\mathrm{CNO}$ (hM3Dq ligand, $0.3 \mathrm{mg} / \mathrm{kg}$ ), caffeine $(20 \mathrm{mg} / \mathrm{kg})$ and $\mathrm{CNO}+$ caffeine $(0.3$ and $20 \mathrm{mg} / \mathrm{kg}$, respectively; Figures 1 and $4 \mathrm{a}, \mathrm{b})$. Treatment significantly affected SWS latency (one-way ANOVA, $\mathrm{F}(1.508,22.12)=707.9$, 
$p<0.0001)$. As previously shown, CNO injection significantly decreased and caffeine significantly increased SWS latency. When $\mathrm{CNO}$ and caffeine were co-injected, SWS latency was similar to control injection, indicating that caffeine, at the dose of $20 \mathrm{mg} / \mathrm{kg}$, and activation of $\mathrm{PZ}$ Vgat neurons counteract each other, resulting in normal SWS latency following co-injection of $\mathrm{CNO}+$ caffeine (Figure 4a2).

Treatment significantly affected sleep-wake amount during the $2 \mathrm{~h}$ post-injection (two-way ANOVA, $\mathrm{F}(9,168)=20.03$, $p<0.0001$; Figure 4b). CNO injection significantly increased SWS amount and caffeine significantly increased wake amount, as compared with control injection. Co-injection of $\mathrm{CNO}+$ caffeine resulted in similar amount of SWS as compared with control injection, further indicating that caffeine, at the dose of $20 \mathrm{mg} / \mathrm{kg}$, and activation of $\mathrm{PZ}$ Vgat neurons counteract each other, resulting in normal SWS amount.

REM sleep latency was also affected by treatment (one-way ANOVA, $\mathrm{F}(1.126,15.76)=15.47, p=0.0009)$ and all treatments significantly delayed REM sleep onset as compared with control injection (Figure 4a3). As previously shown, after activation of $\mathrm{PZ}$ Vgat neurons, the deficit of REM sleep was not compensated by a rebound (Anaclet et al, 2014). On the opposite, caffeine-induced REM sleep deficit during the $4 \mathrm{~h}$ following injection was compensated by a REM sleep rebound during the following 19-7 (dark) period. Interestingly, after co-injection of $\mathrm{CNO}+$ caffeine, mice displayed a REM sleep rebound similar to caffeine alone. This result suggests that caffeine, but not activation of $\mathrm{PZ}{ }^{\mathrm{Vgat}}$ neurons, activates REM sleep homeostatic response and this response is not inhibited by activation of $\mathrm{PZ}$ gat neurons.

As previously described with armodafinil injections, a SWS rebound was seen during the dark period following caffeine injection, at both doses (Figure $4 \mathrm{bB} \&$ Supplementary Table S2). Interestingly, a SWS rebound was seen during the dark period following $\mathrm{CNO}+$ caffeine injection even if the mice did not encounter a significant SWS deficit during the light period (Figure 4bB \& Supplementary Table S2). Similar results were seen at the lower caffeine dosage, indicating that caffeine builds up SWS pressure independently of wake amount.

Both wakefulness and SWS cortical EEG power spectra were affected by the treatment (Figure 4c). Caffeine significantly increased theta, sigma, low- and high-gamma bands during wakefulness, confirming its cortical desynchronizing action (Figure 4cA). In contrast to armodafinil, co-injection of caffeine+CNO induced changes in the SWS cortical EEG and power distribution (Figure $4 \mathrm{cB}$ and d). Caffeine inhibited $\mathrm{PZ}{ }^{\mathrm{Vgat}}$-induced slow-wave-activity, resulting in similar delta power between caffeine+CNO, control injection and baseline power. Moreover, caffeine+CNOinduced SWS was characterized by a significant increase in high-gamma frequency band as compared with both $\mathrm{CNO}$ and control injections. Finally, similar to armodafinil, sigma frequency band, spindle frequency range, was significantly decreased by co-injection of $\mathrm{CNO}+$ caffeine as compared with control injection. This indicates that even if activation of $\mathrm{PZ} \mathrm{Vgat}^{\text {ngarons }}$ can induce SWS, caffeine can block

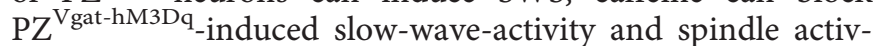
ity, while enhancing fast frequencies characteristic of cortical activation and wakefulness, during SWS, resulting in a poorer quality SWS.
Caffeine dose dependently enhanced wake amount in $\mathrm{PZ}^{\text {Vgat-wt }}$ mice (Supplementary Table S3). A lack of nonspecific interactions between $\mathrm{CNO}$ and caffeine was confirmed by the absence of sleep-wake change between $\mathrm{CNO}$ and $\mathrm{CNO}+$ caffeine injections in control, $\mathrm{PZ}^{\text {Vgat-wt }}$ mice (Supplementary Table S3 \& Supplementary Figure S2), indicating that $\mathrm{CNO}$ does not affect the wake-promoting action of caffeine in $\mathrm{PZ}^{\mathrm{Vgat}-\mathrm{wt}}$ mice.

To confirm that the inhibitory effect of caffeine $(20 \mathrm{mg} / \mathrm{kg})$ on $\mathrm{PZ}^{\mathrm{Vgat}-\mathrm{hM} 3 \mathrm{Dq}}$ induced SWS and its cortical EEG desynchronizing action was not due to non-specific action of high-dose caffeine, nine $\mathrm{PZ}$ Vgat-hM3Dq mice received injections of caffeine $(5 \mathrm{mg} / \mathrm{kg}), \mathrm{CNO}+$ caffeine $(0.3$ and $5 \mathrm{mg} / \mathrm{kg}$, respectively), $\mathrm{CNO}(0.3 \mathrm{mg} / \mathrm{kg})$ and saline as a control injection. At the dose of $5 \mathrm{mg} / \mathrm{kg}$ (Figure 5 , Supplementary Table S2) caffeine significantly delayed SWS latency and REM sleep latency. Wakefulness was increased during the $2 \mathrm{~h}$ post caffeine $(5 \mathrm{mg} / \mathrm{kg})$ injection. $\mathrm{CNO}+$ caffeine counteracted each other, resulting in similar amount of SWS as compared with control during the $2 \mathrm{~h}$ post injection. Cortical EEG power spectral analysis revealed similar phenotypes as described for the high dose of caffeine (Figures $5 \mathrm{~b}$ and $4 \mathrm{c}$ ). At the low dose, caffeine was still able to enhance sigma and high gamma bands as compared with control injection. Interestingly, when co-injected with $\mathrm{CNO}$, caffeine $(5 \mathrm{mg} / \mathrm{kg})$ was still able to enhance cortical EEG high frequencies. These results suggest that activation of $\mathrm{PZ}^{\mathrm{VGAT}}$ neurons and caffeine counteract each other in a specific way.

\section{DISCUSSION}

In the present study, we show that activation of $\mathrm{PZ}$ Vgat neurons is capable of counteracting the potent wakepromoting properties of two psychostimulants, armodafinil and caffeine. This latter finding provides, to our knowledge, the first evidence that activation of a specific and delimited neuronal population is sufficient to induce and maintain SWS, even when the sleep-wake network is strongly pharmacologically biased toward cortical activation and wakefulness.

\section{Technical Considerations}

We undertook a myriad of control experiments to demonstrate that the observed phenotypes resulting from the chemogenetic and pharmacologic experiments were specific to the treatment. We first show that at the dose of $0.3 \mathrm{mg} / \mathrm{kg}$, $\mathrm{CNO}$ does not influence baseline sleep-wake in $\mathrm{PZ}$ Vgat-WT (non-DREADDs expressing) mice. This result confirms that the EEG and behavioral phenotypes observed in this study were due to chemogenetic activation of $\mathrm{PZ}{ }^{\text {Vgat }}$ neurons via $\mathrm{hM} 3 \mathrm{Dq}$ receptors as well as replicates previous results reported by our group (Anaclet et al, 2014). We, moreover, show that both armodafinil and caffeine are potently wakepromoting and that both drugs dose-dependently increase wakefulness in mice, as have been previously reported (Parmentier et al, 2007). In addition, administration of armodafinil or caffeine both significantly enhanced cortical desynchronization and fast frequencies during wakefulness, confirming that the absence of a waking phenotype observed following co-administration with $\mathrm{CNO}$ is due to activation of 
Wakefulness

aA

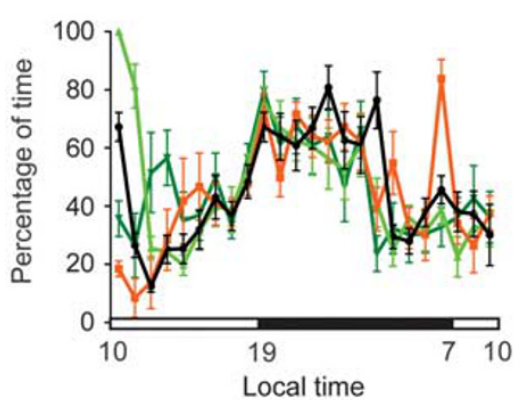

bA

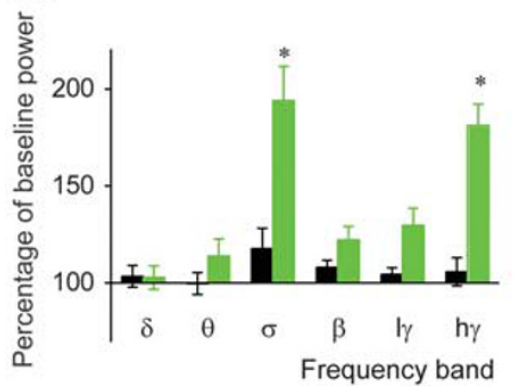

Slow-Wave-Sleep

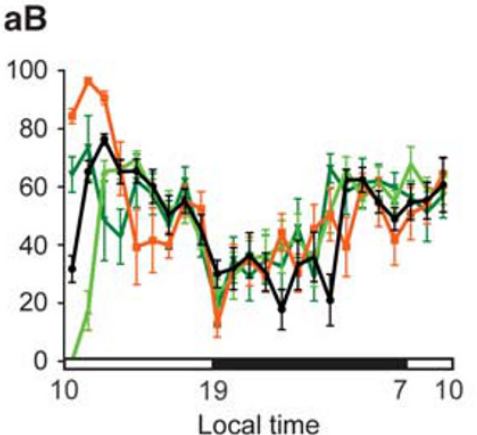

bB

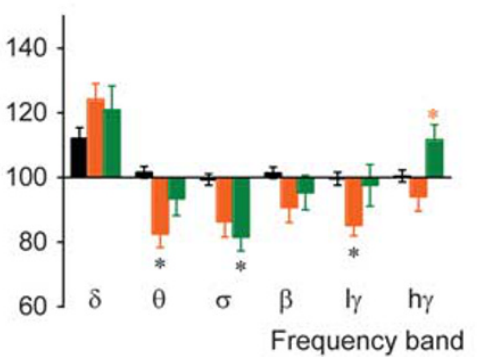

Figure 5 Sleep-wake and EEG responses to injections of vehicle, CNO $(0.3 \mathrm{mg} / \mathrm{kg})$, caffeine $(5 \mathrm{mg} / \mathrm{kg})$ and $\mathrm{CNO}+\mathrm{caffeine}(0.3 \mathrm{mg} / \mathrm{kg}$ and $5 \mathrm{mg} / \mathrm{kg}$, respectively), in $\mathrm{PZ} Z^{V g a t-h M 3 D q}$ mice. (a) Hourly amount of the vigilance stages, $n=9$ mice. (b) Power spectrum changes (\% \pm SEM) over baseline during the 3- $h$ post-injection period for vehicle injection as compared with the I-h post-injection period for $\mathrm{CNO}$, caffeine and $\mathrm{CNO}+$ caffeine administration and the quantitative changes $(\% \pm \mathrm{SEM})$ in power for the delta $(8: 0.5-5 \mathrm{~Hz})$, theta $(\theta: 5-9 \mathrm{~Hz})$, sigma $(\sigma: 9-15 \mathrm{~Hz})$, beta $(\beta$ : I5-30 Hz), low gamma $(\mathrm{l} \gamma$ : 30-60 Hz) and high gamma (hy: 60-120 Hz) frequency bands, $n=5$ mice. Black star, $p<0.05$ as compared with control injection; orange star, $p<0.05$ as compared with CNO injection, two-way ANOVA corrected with a Bonferroni's multiple comparisons test.

$\mathrm{PZ}{ }^{\text {Vgat }}$ neurons and not a deficit of a waking response to the psychostimulants in these mice. We also show that coinjection of $\mathrm{CNO}$ with armodafinil or caffeine did not affect the wake-promoting action of the two psychostimulants in control mice, indicating an absence of nonspecific effects of $\mathrm{CNO}$ on the circuit and/or molecular targets of armodafinil or caffeine. Hence, the sleep-wake changes described in $\mathrm{PZ}^{\mathrm{Vgat}-\mathrm{hM} 3 \mathrm{Dq}}$ mice are a direct result of the activation of $\mathrm{PZ}{ }^{\text {Vgat }}$ neurons. Also, when co-injected with $\mathrm{CNO}$, both armodafinil and caffeine were able to exert a wakepromoting effect after the first $2-3 \mathrm{~h}$ post-injection, which is temporally coincident with CNO washout, that is, CNO is no longer detectable in the plasma (Wess et al, 2013). This latter finding indicates that activation of $\mathrm{PZ}^{\mathrm{Vgat}}$ neurons by $\mathrm{CNO}$ is able to antagonize the wake-promoting action of the psychostimulants and that these effects are reversible. Taken together, results from our control studies provide high confidence that the observed phenotypes reflected neuronal activation/inhibition and not interactions or nonspecific actions of the drugs.

We chose to administer our wake-promoting compounds $3 \mathrm{~h}$ after lights-on (10:00 A.M., ZT3), which is a time of day that sleep drive is at or near its maximum in the mouse (Franken et al, 1999). The rationale for administering our psychostimulants during the sleep period was that we wanted to maximize the magnitude of the wake-promotion following psychostimulant administration. We felt that maximizing the magnitude and duration of the effect of drug administration would facilitate ascertaining whether the attenuating effect of concurrent activation of $\mathrm{PZ} \mathrm{Vgat}^{\mathrm{Vga}}$ neurons, if any, was partial or complete. It is moreover the case that the effects of modafinil and caffeine are more robust when administered during the sleep period than during the wake period. For example, administration of modafinil (64 mg/kg, i.p.) at the light-dark transition (that is, near or at peak waking drive) produces a rather modest $(\sim 30 \mathrm{~min}$ or $17 \%)$ increase in wakefulness during the $3 \mathrm{~h}$ post-injection period (Lin et al, 2008), whereas administration of modafinil (32 mg/kg, i.p.) during the light period doubles the amount of wakefulness during the 4-h post-injection period (Parmentier et al, 2007). Also, in our previous work, we showed that activation of $\mathrm{PZ}$ GABAergic neurons during the dark (waking) phase enhanced slow-wave-sleep to a greater degree than activation of these neurons during the light (sleep) period (Anaclet et al, 2014). Hence, our experimental design emphasized a time of day when the effects of the wake-promoting drugs were at or near their maximal effect, whereas the effects of PZ GABA activation was not. As such, any time of day influence should have biased wake, and not sleep, in our experiments. Nevertheless, the timing of drug administration is a critical consideration and could have influenced our results through other mechanisms. For example, the circadian rhythm of dopamine transporter (DAT) activity (Ferris et al, 2014) could have modified the magnitude of armodafinil's wake-promoting action. DAT activity appears to reach a maximum at ZT9-10, 2-3 h before lights-off, and is at a minimum at ZT19-20, during the second half of the dark period (Ferris et al, 2014). At the time of the injections 
in the present study, ZT3, DAT activity appears to be at its mean level of activity. Similarly, the wake-promoting action of caffeine could have time-of-day dependency given that adenosine levels increase in the basal forebrain and the cortex during period of wakefulness and decrease during period of sleep (Kalinchuk et al, 2011). At ZT3, which is $3 \mathrm{~h}$ into the sleep period, adenosine levels would have been elevated, whereas at lights-off adenosine levels would have been low. Given the strong and dose-dependent wakepromoting action of armodafinil and caffeine and the more limited enhancement of sleep following activation of $\mathrm{PZ}$ Vgat neurons at ZT3, we are confident that similar, if not more robust, results would have been obtained if the experiments were performed at lights-off.

\section{Activation of $\mathrm{PZ} \mathrm{V}^{\text {Vgat }}$ Neurons Completely Blocks the Wake Promoting Action of Armodafinil}

Racemic modafinil and its R-enantiomer, armodafinil, are potent wake-promoting drugs used for the treatment of sleepiness in a myriad of disorders (Dell'Osso et al, 2014). To date, the only mouse model in which modafinil demonstrably failed to induce wakefulness is the dopamine D2 receptor knockout mouse when pretreated with a dopamine $\mathrm{D} 1$ receptor antagonist (Qu et al, 2008), indicating that modafinil wake-promoting action is mediated by dopamine signaling. Here we show, for the first time, that the wakepromoting action of armodafinil can be completely antagonized by activation of a delimited node of medullary GABAergic neurons. We specifically showed that $\mathrm{PZ}^{\text {Vgat }}{ }_{-}$ induced SWS latency and amount as well as cortical SWA were not diminished by administration of high-dose armodafinil. These results not only emphasize the potent ability of $\mathrm{PZ} \mathrm{Vgat}^{\text {vat }}$ neurons to produce and maintain sleep, but may also provide new insights into the wake-promoting action of modafinil, something that has remained enigmatic. To this end, modafinil is a DAT inhibitor and available evidence suggests that modafinil enhances wakefulness by increasing dopaminergic transmission (Wisor, 2013). However, modafinil's inhibitory action on DAT is weak and is unlikely to account in full for its potent wake-promoting action, suggesting additional, unknown mechanisms. The findings from the present study raise the interesting possibility that $\mathrm{PZ}^{\mathrm{Vgat}}$ neurons may play an important role in modafinil's wake-promoting action. For example, armodafinil may exert its wake-promoting effect through direct inhibition of $\mathrm{PZ}$ Vgat neurons. In the present study, $\mathrm{PZ}$ Vgat neurons were activated via the $\mathrm{hM} 3 \mathrm{Dq}$ receptor and as such any direct inhibitory action of armodafinil on $\mathrm{PZ}^{\mathrm{Vgat}}$ neurons may have been masked. To test this putative inhibition of $\mathrm{PZ}{ }^{\text {Vgat }}$ neurons by armodafinil, future studies could be contemplated, in which armodafinil is administered to animals with $\mathrm{PZ}{ }^{\text {Vgat }}$ lesions, as was previously done with the sleep-promoting ventrolateral preoptic area (Vetrivelan et al, 2014), or administered to $\mathrm{PZ}^{\mathrm{Vgat}}$ knockout mice (Anaclet et al, 2012). Another possibility is that $\mathrm{PZ}^{\mathrm{Vgat}}$ neurons may strongly inhibit all wake-promoting neurotransmitter systems that are potentiated by modafinil such as histamine, noradrenaline, serotonine, GABA, and glutamate (Gerrard and Malcolm, 2007). In the present study, strong, but physiologic, stimulation of $\mathrm{PZ}^{\text {gat }}$ neurons via the DREADDs may have thus potently inhibited all cellular targets of armodafinil, in particular, those that are postsynaptic targets of the GABAergic PZ, although the exact post-synaptic targets of $\mathrm{PZ} \mathrm{Vgat}^{\mathrm{Vga}}$ neurons remains unresolved. Anatomic mapping studies of $\mathrm{PZ}{ }^{\mathrm{Vgat}}$ afferents have yet to be provided, but are eagerly awaited, in particular as they could reveal key downstream circuit nodes that mediate armodafinil's arousal-promoting properties. Interestingly, and somewhat paradoxically, we found that administration of armodafinil appeared to potentiate the SWA-promoting action induced by activation of $\mathrm{PZ}^{\mathrm{Vgat}}$ neurons, resulting in even deeper SWS than seen with CNO alone. Indeed, SWA (that is, a marker of sleep stage 3 in humans) was enhanced and spindle activity (ie, feature of sleep stage 2 in humans) were reduced after $\mathrm{CNO}+$ armodafinil as compared with CNO alone. Mechanistically, how armodafinil could potentiate the sleep-promoting action of $\mathrm{PZ}{ }^{\mathrm{Vgat}}$ neurons remains an open question.

Another unexpected finding in our study, in particular as it stands in contrast to previous reports in mouse, cat and human subjects (Buguet et al, 1995; Lin, 2000; Parmentier et al, 2007; Wisor et al, 2006), was that SWS was increased for about an hour, and REM sleep for about $10 \mathrm{~min}$, during the dark period following the injection $(9-21 \mathrm{~h}$ post injection) of both armodafinil and CNO+armodafinil, indicating a sleep rebound. These previous studies had found that modafinil did not produce sleep rebound. While it is difficult to explain this discrepancy, it is the case that few studies using modafinil or armodafinil appear to have analyzed the post-injection sleep-wake data for a full $24 \mathrm{~h}$, as we did here. Given the observed sleep rebound in our study, we would argue that armodafinil can influence sleep homeostatic drive.

\section{Activation of $\mathrm{PZ}$ Vgat Neurons Partially Blocks the Wake-Promoting Action of Caffeine}

Studies in humans have shown that caffeine intake at bed time increases sleep latency, decreases SWS amount and SWA and increases sigma/beta frequencies during SWS (Drapeau et al, 2006; Landolt et al, 1995). Similar results have been described on recovery sleep when caffeine is administered at the end of a sleep deprivation period (Landolt et al, 2004). In this study, we show that coinjection of CNO+caffeine significantly increased SWS latency and decreased SWS amount and SWA, as compared with administration of CNO alone. Thus, similar quantitative/qualitative parameters of SWS were observed between control (saline) and $\mathrm{CNO}+$ caffeine injections. A parsimonious interpretation of this finding is that caffeine antagonizes $\mathrm{PZ}{ }^{\mathrm{Vgat}} \mathrm{SWS}$-promoting action and vice versa.

It has been suggested that caffeine may promote wakefulness by blocking adenosine-mediated inhibition of basal forebrain (BF) neurons via adenosine A1 receptor (Basheer et al, 2001). Given that (1) $\mathrm{PZ}^{\mathrm{Vgat}}$ neurons enhance SWS at least in part by inhibiting parabrachial nucleus $\rightarrow \mathrm{BF} \rightarrow$ cortex ascending arousal pathway (Anaclet et al, 2014); (2) that activation of $\mathrm{BF}$ cholinergic neurons can block cortical SWA during SWS, while activation of BF GABAergic neurons strongly enhance cortical desynchronization (Anaclet et al, 2015); and (3) increased adenosine concentration in the $\mathrm{BF}$ may be the molecular substrate for sleep homeostasis (Porkka-Heiskanen et al, 2000), we hypothesize 
that the BF may be a key circuit node for $\mathrm{PZ}$ Vgat $\mathrm{SWS}$ promoting action and that $\mathrm{PZ} \mathrm{Vgat}^{\mathrm{Vg}}$ inhibition of the $\mathrm{BF}$ could be mediated, at least in part, by adenosine. Given, moreover, that fast cortical EEG frequencies were increased following $\mathrm{CNO}+$ caffeine as compared with control injections, it is clear that caffeine is still able to desynchronize the cortical EEG even when $\mathrm{PZ}{ }^{\mathrm{Vgat}}$ neurons are active. The neuronal substrate of caffeine-induced cortical desynchronization remains to be elucidated but we hypothesize that caffeine may act downstream of $\mathrm{PZ}$ Vgat neurons, possibly directly on cortical neurons by blocking neuronal adenosine A1 receptors (Bjorness et al, 2016) or, as previously shown, on adenosine A2A receptors of the nucleus accumbens shell (NAs; (Lazarus et al, 2011)). Whether or not $\mathrm{PZ}^{\mathrm{Vgat}}$ neurons influence directly (synaptically) or indirectly (via other synaptic relays), the activity of NAs neurons is currently unknown, but stands to be an exciting area of future investigative work. Finally, and as previously described (Parmentier et al, 2007), caffeine administration in the present study, even at the lowest dose and combined with $\mathrm{CNO}$, resulted in a sleep rebound during the dark period following injections, substantiating a direct influence of caffeine on sleep homeostatic drive.

In sum, these findings provide the first evidence that activation of PZ GABA-releasing neurons actively maintains SWS and cortical SWA. That the wake-promoting action of two widely used psychostimulants can be counteracted by activation of this delimited sleep-promoting cell population underscores the potency of control that $\mathrm{PZ}{ }^{\text {Vgat }}$ neurons can exert on neural function, in particular behavioral state control. Outcomes from this study also raise new questions regarding the mechanism of action of armodafinil and suggest a possible shared circuit substrate by which armodafinil and caffeine produce arousal and that $\mathrm{PZ} \mathrm{Vgat}^{\mathrm{V}}$ neurons drive and maintain SWS.

\section{FUNDING AND DISCLOSURE}

This work was funded by National Institutes of Health grants K99 MH103399 (C.A.) and R01NS092652 (P.M.F.). The authors declare no conflict of interest.

\section{ACKNOWLEDGMENTS}

We are grateful to Quan Hue $\mathrm{Ha}$, Minh Ha, Myriam Debryune and Rebecca Broadhurst for superb technical assistance.

\section{REFERENCES}

Anaclet C, Ferrari L, Arrigoni E, Bass CE, Saper CB, Lu J et al (2014). The GABAergic parafacial zone is a medullary slow wave sleep-promoting center. Nat Neurosci 17: 1217-1224.

Anaclet C, Lin JS, Vetrivelan R, Krenzer M, Vong L, Fuller PM et al (2012). Identification and characterization of a sleep-active cell group in the rostral medullary brainstem. I Neurosci 32: 17970-17976.

Anaclet C, Pedersen NP, Ferrari LL, Venner A, Bass CE, Arrigoni E et al (2015). Basal forebrain control of wakefulness and cortical rhythms. Nat Commun 6: 8744.
Anaclet C, Pedersen NP, Fuller PM, Lu J (2010). Brainstem circuitry regulating phasic activation of trigeminal motoneurons during REM sleep. PLoS ONE 5: e8788.

Basheer R, Rainnie DG, Porkka-Heiskanen T, Ramesh V, McCarley RW (2001). Adenosine, prolonged wakefulness, and A1-activated NF-kappaB DNA binding in the basal forebrain of the rat. Neuroscience 104: 731-739.

Bjorness TE, Dale N, Mettlach G, Sonneborn A, Sahin B, Fienberg AA et al (2016). An adenosine-mediated glial-neuronal circuit for homeostatic sleep. J Neurosci 36: 3709-3721.

Buguet A, Montmayeur A, Pigeau R, Naitoh P (1995). Modafinil, $\mathrm{d}$-amphetamine and placebo during 64 hours of sustained mental work. II. Effects on two nights of recovery sleep. J Sleep Res 4: 229-241.

Cornil CA, Balthazart J, Motte P, Massotte L, Seutin V (2002). Dopamine activates noradrenergic receptors in the preoptic area. J Neurosci 22: 9320-9330.

Dell'Osso B, Dobrea C, Cremaschi L, Arici C, Altamura AC (2014). Wake-promoting pharmacotherapy for psychiatric disorders. Curr Psychiatry Rep 16: 524.

Drapeau C, Hamel-Hebert I, Robillard R, Selmaoui B, Filipini D, Carrier J (2006). Challenging sleep in aging: the effects of $200 \mathrm{mg}$ of caffeine during the evening in young and middle-aged moderate caffeine consumers. J Sleep Res 15: 133-141.

Ferris MJ, Espana RA, Locke JL, Konstantopoulos JK, Rose JH, Chen $\mathrm{R}$ et al (2014). Dopamine transporters govern diurnal variation in extracellular dopamine tone. Proc Natl Acad Sci USA 111: E2751-E2759.

Fiocchi EM, Lin YG, Aimone L, Gruner JA, Flood DG (2009). Armodafinil promotes wakefulness and activates Fos in rat brain. Pharmacol Biochem Behav 92: 549-557.

Franken P, Malafosse A, Tafti M (1999). Genetic determinants of sleep regulation in inbred mice. Sleep 22: 155-169.

Fuller P, Sherman D, Pedersen NP, Saper CB, Lu J (2011). Reassessment of the structural basis of the ascending arousal system. J Comp Neurol 519: 933-956.

Gallopin T, Luppi PH, Rambert FA, Frydman A, Fort P (2004). Effect of the wake-promoting agent modafinil on sleep-promoting neurons from the ventrolateral preoptic nucleus: an in vitro pharmacologic study. Sleep 27: 19-25.

Galvalisi M, Prieto JP, Martinez M, Abin-Carriquiry JA, Scorza C (2017). Caffeine induces a stimulant effect and increases dopamine release in the nucleus accumbens shell through the pulmonary inhalation route of administration in rats. Neurotox Res 31: 90-98.

Gerrard P, Malcolm R (2007). Mechanisms of modafinil: A review of current research. Neuropsychiatr Dis Treat 3: 349-364.

Kalinchuk AV, McCarley RW, Porkka-Heiskanen T, Basheer R (2011). The time course of adenosine, nitric oxide (NO) and inducible NO synthase changes in the brain with sleep loss and their role in the non-rapid eye movement sleep homeostatic cascade. J Neurochem 116: 260-272.

Landolt HP, Dijk DJ, Gaus SE, Borbely AA (1995). Caffeine reduces low-frequency delta activity in the human sleep EEG. Neuropsychopharmacology 12: 229-238.

Landolt HP, Retey JV, Tonz K, Gottselig JM, Khatami R, Buckelmuller I et al (2004). Caffeine attenuates waking and sleep electroencephalographic markers of sleep homeostasis in humans. Neuropsychopharmacology 29: 1933-1939.

Lazarus M, Shen HY, Cherasse Y, Qu WM, Huang ZL, Bass CE et al (2011). Arousal effect of caffeine depends on adenosine A2A receptors in the shell of the nucleus accumbens. J Neurosci 31: 10067-10075.

Lin JS (2000). Brain structures and mechanisms involved in the control of cortical activation and wakefulness, with emphasis on the posterior hypothalamus and histaminergic neurons. Sleep Med Rev 4: 471-503.

Lin JS, Dauvilliers Y, Arnulf I, Bastuji H, Anaclet C, Parmentier R et al (2008). An inverse agonist of the histamine $\mathrm{H}(3)$ receptor 
improves wakefulness in narcolepsy: studies in orexin-/- mice and patients. Neurobiol Dis 30: 74-83.

Lin JS, Hou Y, Jouvet M (1996). Potential brain neuronal targets for amphetamine-, methylphenidate-, and modafinil-induced wakefulness, evidenced by c-fos immunocytochemistry in the cat. Proc Natl Acad Sci USA 93: 14128-14133.

Nall AH, Shakhmantsir I, Cichewicz K, Birman S, Hirsh J, Sehgal A (2016). Caffeine promotes wakefulness via dopamine signaling in Drosophila. Sci Rep 6: 20938.

Parmentier R, Anaclet C, Guhennec C, Brousseau E, Bricout D, Giboulot $\mathrm{T}$ et al (2007). The brain H3-receptor as a novel therapeutic target for vigilance and sleep-wake disorders. Biochem Pharmacol 73: 1157-1171.

Paxinos GT, Franklin K (2001). The Mouse Brain in Stereotaxic Coordinates, 2nd edn. Academic: San Diego.

Porkka-Heiskanen T, Strecker RE, McCarley RW (2000). Brain sitespecificity of extracellular adenosine concentration changes during sleep deprivation and spontaneous sleep: an in vivo microdialysis study. Neuroscience 99: 507-517.

Qu WM, Huang ZL, Xu XH, Matsumoto N, Urade Y (2008). Dopaminergic D1 and D2 receptors are essential for the arousal effect of modafinil. J Neurosci 28: 8462-8469.
Scammell TE, Estabrooke IV, McCarthy MT, Chemelli RM, Yanagisawa M, Miller MS et al (2000). Hypothalamic arousal regions are activated during modafinil-induced wakefulness. J Neurosci 20: 8620-8628.

Vetrivelan R, Saper CB, Fuller PM (2014). Armodafinil-induced wakefulness in animals with ventrolateral preoptic lesions. Nat Sci Sleep 6: 57-63.

Volkow ND, Wang GJ, Logan J, Alexoff D, Fowler JS, Thanos PK et al (2015). Caffeine increases striatal dopamine D2/D3 receptor availability in the human brain. Transl Psychiatry 5: e549.

Vong L, Ye C, Yang Z, Choi B, Chua S Jr, Lowell BB (2011). Leptin Action on GABAergic Neurons Prevents Obesity and Reduces Inhibitory Tone to POMC Neurons. Neuron 71: 142-154.

Wess J, Nakajima K, Jain S (2013). Novel designer receptors to probe GPCR signaling and physiology. Trends Pharmacol Sci 34: 385-392.

Wisor J (2013). Modafinil as a catecholaminergic agent: empirical evidence and unanswered questions. Front Neurol 4: 139.

Wisor JP, Dement WC, Aimone L, Williams M, Bozyczko-Coyne D (2006). Armodafinil, the R-enantiomer of modafinil: wakepromoting effects and pharmacokinetic profile in the rat. Pharmacol Biochem Behav 85: 492-499.

Supplementary Information accompanies the paper on the Neuropsychopharmacology website (http://www.nature.com/npp) 